\title{
The Language and Learning study (SOL): Study profile and results so far
}

\author{
Mari Vaage Wang and Synnve Schjølberg \\ Norwegian Institute of Public Health, Division of Mental Health, Oslo, Norway \\ E-mail: mawa@fhi.no
}

\begin{abstract}
Language development is associated with cognitive, social and behavioral performance. A healthy language development is crucial for everyday functioning both during childhood and in adulthood. Language impairment is considered one of the most common neurodevelopmental impairments in children. The language and learning study (SOL) is a platform for multiple language projects. The main aim of SOL is to provide the best possible knowledge base for understanding causes and developmental trajectories of language impairments. Our results so far include knowledge about developmental trajectories of normal language development as well as developmental impairments. Additionally a number of risk and protective factors have been studied.
\end{abstract}

This is an open access article distributed under the Creative Commons Attribution Licence, which permits unrestricted use, distribution, and reproduction in any medium, provided the original work is properly cited.

\section{About LANGUAGe AND LEARNing}

Language skills vary greatly, both between individuals, and within each child throughout development. During the first years of life children's language skills develop from preverbal communication to conversations using and understanding long and complicated sentences. Many factors influence the rate of this development. Although most children develop language skills seemingly effortless, language impairments affect between $7-10 \%$ of preschool children and are considered one of the most common neurodevelopmental difficulties $(1,2)$. Difficulties with language learning can manifest itself in various ways; through late emergence of language, slow vocabulary growth or difficulties in mastering grammar and discourse skills (3). Cooccurrence of language difficulties and other developmental problems are common, and the association with reading impairment is particularly high $(4,5)$. Language impairments are associated with poor educational outcomes, in addition to other unfavorable outcomes such as higher unemployment rates and increased vulnerability to mental disorders, psychosocial problems and overall social disadvantage $(6,7)$. The significance of language impairments has received political attention in Norway through a white paper (8) which refers to language impairments as amongst the primary causes of life-long social inequality. Thus language and learning becomes important topics both for research and political purposes.

There is a lack of studies investigating language development longitudinally in large population based cohorts. There is growing evidence that child-, familyand environmental factors in the first year of life predicts language outcomes at 18 months (9) and two years $(10,11)$. Recent longitudinal studies beginning in infancy have reported instability in language outcomes of children between 2 through 7 years, with some language impairments being detected for the first time at 4 years of age (2). In addition, there is a group of children with late language emergence at 2-3 years whose problems seem to be resolved by 5 , but reappear as language and reading problems in the school years (12). It appears that early communication delay is only one of several pathways to later language disorders. Utilizing data from large sample sizes measuring language skills repeatedly through development gives opportunities to investigate such pathways between behavioral markers, developmental trajectories and causal factors.

\section{The relation between language and other developing areas}

In understanding the development of language skills it is important to also consider the relationship to other developmental domains. Co-occurrence of developmental language impairments and delays in other developmental areas are frequent. Between 40 and $90 \%$ of children with language delay have additional developmental or behavioral problems such as aggression, hyperactivity and poor social skills (13). During preschool years development is characterized by rapid changes. What is considered normal at one point in time quickly changes to being abnormal at another point in time. Knowledge about how symptoms of different developmental delays influence each other over time is essential to understand development of language, and to understand why language sometimes does not develop as expected.

\section{Day care attendance and language development}

Understanding the environmental and social factors influencing children's language development is important. Day care attendance is common across all preschool years in Norway, and more than $96 \%$ of $3-5-$ year olds attend public subsidized center care (14). The percentage of children who attend childcare has increased steadily over the past 10 years. We still know little about how various factors in center-based childcare affect children's well-being, development 
and learning. Earlier research has shown that day care quality is associated with developmental outcomes in children. In addition to being affordable for most parents, day care centers in Norway are on average of considerably higher quality than in many other countries. This together with the increased rates of attendance makes Norwegian children a unique source for investigating quality in day care centers in association to language and other developmental outcomes in preschool years as well as long term outcomes in school.

\section{LANGUAGE AND LEARNING STUDY (SOL)}

The Language and Learning study (SOL - Språk og Læring) originates from a collaboration between the Norwegian Institute of Public Health (NIPH) and the Ministry of Education (KD) in 2007. Both had a great interest in exploring children's language development longitudinally and investigate factors that contribute to delayed or deviant language development. The interests were both in biological risk factors as well as environmental factors with a special focus on the use of childcare when the children are very young.

The first grant funded the project "Language Delay - Causes and Pathways". This project takes advantage of the unique dataset available through The Norwegian Mother and Child Cohort Study (MoBa). Figure 1 shows a description of projects included in SOL and the timeline for the expansions. It addressed several research questions:

1) What influences growth and change in language skills in preschool children;

2) What are the risk factors for language impairment in preschool children and

3) Does attending childcare influence language development in preschool children.

This first grant funded a new parental questionnaire in the MoBa study, completed when the children were five years old. This questionnaire focused on language and other neurodevelopmental disorders. The grant from $\mathrm{KD}$ also funded analytical work through a $\mathrm{PhD}$ student studying the association between attending childcare and risk of late language development or behavioral disorders at three and five years of age.

Two additional grant proposals for $\mathrm{PhD}$ projects were accepted with funding by EXTRA funds from the Norwegian Foundation for Health and Rehabilitation. These two projects explored in more detail trajectories in language development looking specifically on the relationship between language and gestural development as well as studying the relationship between language and motor skill from three to five years. A PostDoc was added to the SOL study through funding from the Norwegian Research Council (NFR) looking at the relationship between children's language skills at three in children growing up in families with low income, and exploring in particular whether attending childcare was associated with better language or behavioral outcome in children from these families.
The collaboration with KD continued and in 2010 they funded an extension of the former project: "Language development and learning outcomes from 6 months to 8 years - the influence of home, childcare and school". The grant contributed to an added data collection from childcare centers to be completed by child care teachers (CCQ) and from schools to be completed by school teachers (SQ) when the children were 8 years old. In addition the grant partially funded the 8 year parent questionnaire in MoBa. A particular focus in this project is to study language development and learning outcomes in association with different quality indicators in childcare units and school class settings. With the new data collection a renewed focus on children with special needs was emphasized.

A new grant proposal for a $\mathrm{PhD}$ was accepted with funding by EXTRA funds from the Norwegian Foundation for Health and Rehabilitation. This project explores in detail emotional regulation in children with language impairments in relation to temperamental characteristics. As part of the focus on children with special needs, a paper on the relationship between attention problems and language development from 18 to 36 months in premature children has been published (15), and followed with a grant application on prematurity, language development and later academic success.

Grant applications focusing on the relationship between quality aspects in childcare, child and family characteristics and school outcome will have priority the coming two years. The dataset will be linked to Registries for scores on National school tests, usually done in $5^{\text {th }}$ grade that involves reading and mathematics.

In 2012, a further extension to the SOL-study was attained with a four-year funding from the Norwegian Research Council through the program FRIMEDBIO for a clinical study of 8 year old children with a history of language impairment; "Developmental trajectories of childhood language impairment: Understanding the role of behavioral and biological markers" (Language-8/Språk-8). The study focuses on developmental trajectories of childhood language impairment, and aims at better understanding the role of behavioral markers and heritability. This study will expand our knowledge about children with language disorders in Norway, in terms of cognitive-linguistic profiles, early markers, and developmental trajectories. Additionally, the study collects saliva samples from the families for DNA analysis and collects supplementary questionnaires from parents and school teachers. The clinical study also supports a validation study of scales used in the 5 year MoBa questionnaire.

\section{RESEARCH QUESTIONS ACROSS THE DIFFERENT PROJECTS IN SOL}

The main aim of the SOL study is to identify causes and risk factors for late language development and language disorders, and to better understand the tra- 


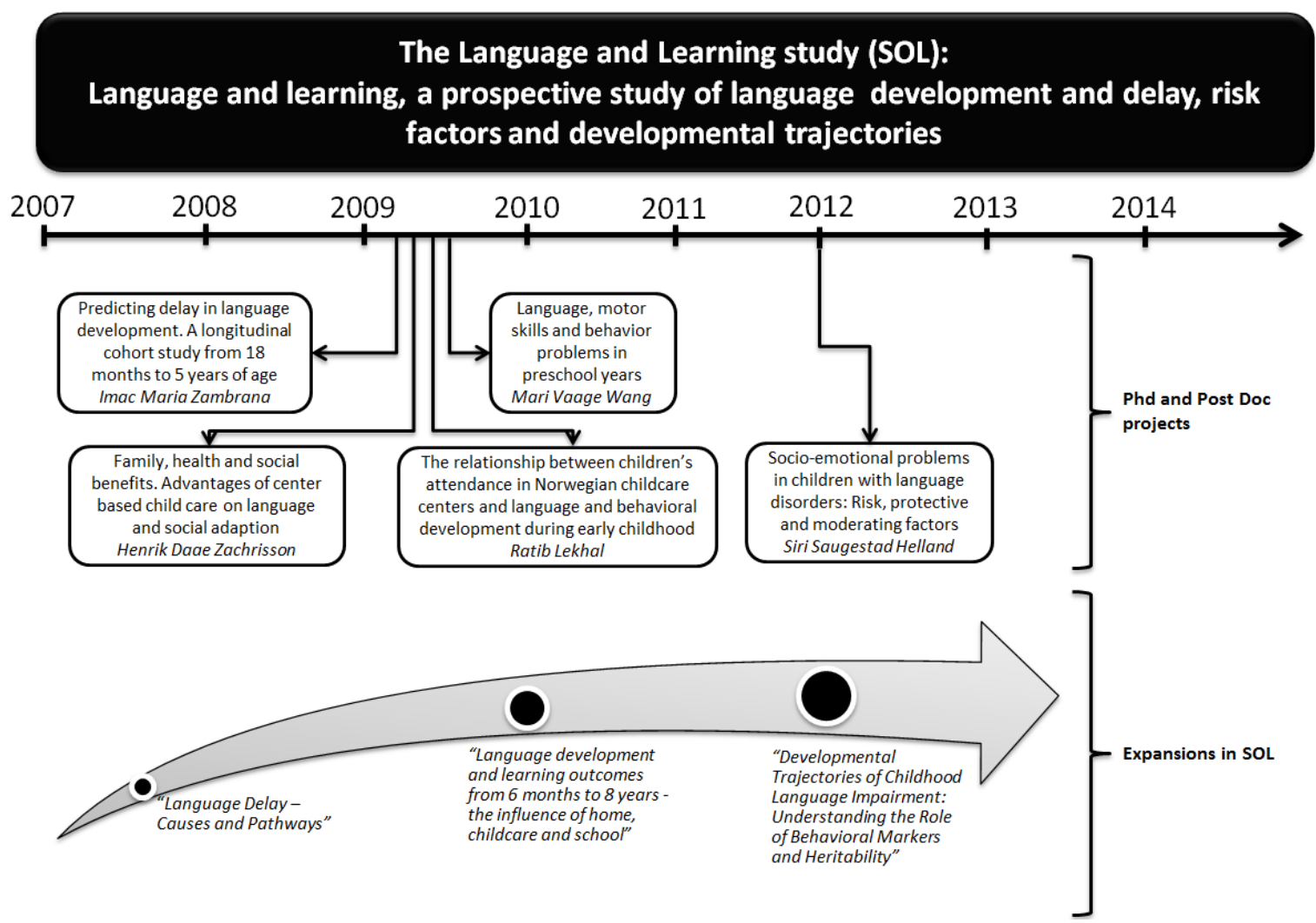

Figure 1. Timeline and overview of the projects included in the SOL study.

jectories of language development. This has led to a variety of research questions linked to the expansions and added substudies in SOL, and several of these remains to be investigated. Some examples are:

- What are the causes and risk factors for developmental language impairments?

- Can trajectories of early language development differentiate between children who will or will not have language impairments and/or later reading problems?

- What are the developmental association between language impairments and other developmental problems, such as for example inattention, social skills, and emotional- and behavior problems?

- Which factors identified in preschool years predict language and reading development, and performance in school?

- Do different aspects of day care quality have different associations to typically developing children and children with different vulnerabilities or special needs?

\section{METHODS}

\section{Design and data collection}

SOL utilizes data from the Norwegian Mother and Child Study (MoBa) as well as additional data. Most $\mathrm{PhD}$ and Post Doc projects so far utilize questionnaire information through the MoBa dataset in combination with data from pregnancy and birth through the linkage to the Medical Birth Registry. MoBa provides information about the mother and child's health through maternal reports in questionnaires filled in when the children are $6,18,36$ months as well as 5,7 and 8 years of age.

In the five-year $\mathrm{MoBa}$ questionnaire parents rate language competence and delay across different measures, in addition to motor skills, play and social skills as well as inattention and behavioral disorders. In the eight-year MoBa questionnaire parents rate language competence as well as inattention/hyperactivity and behavioral disorders. Questions on social skills and presence of autistic like symptoms are also included. Parents rate the child's interest in and skills in reading and writing as reported to parents by the schoolteacher based on the child's test-scores on the national assessment done in $1^{\text {st }}$ and $2^{\text {nd }}$ grade.

A subsample of 24000 families receives a Childcare questionnaire (CCQ), asking parents to consent to that the preschool teacher can fill in the questionnaire. The CCQ contains information about staff education, staff/child ratio, and several measures of priorities in curriculum activities among other quality indicators. In addition the preschool teacher rates the child on several of the same language and behavioral measures that the parents rated in the parent questionnaire. The first families that have received the CCQ at five years of age will receive the School questionnaire (SQ) this autumn (2014), when the children turn 8 years.

The validation study of developmental measures is 
Table 1. Description of inclusion criteria for Language-8.

\begin{tabular}{|l|l|}
\hline Criterion 1 & Children reported with language delay at 5 years \\
\hline Criterion 2 & $\begin{array}{l}\text { Children reported as being assessed for language impairment at } 5 \text { years or earlier with a conclusion of } \\
\text { Expressive only or Expressive/Receptive language problems }\end{array}$ \\
\hline Criterion 3 & $\begin{array}{l}\text { Children scoring 1 standard deviation or further below the MoBa population mean across a standardized } \\
\text { measure of 6 language scales }\end{array}$ \\
\hline Criterion 4 & Children reported with language delay at 8 years \\
\hline Criterion 5 & $\begin{array}{l}\text { Children scoring 1 standard deviation or further below the MoBa population mean across a standardized } \\
\text { measure of 2 language scales }\end{array}$ \\
\hline
\end{tabular}

Table 2. Clinical tests in Language- 8 .

\begin{tabular}{|l|l|}
\hline Function & Measure \\
\hline IQ-measure & Wechsler Abbreviated Scale of Intelligence (WASI $\left.{ }^{\mathrm{TM}}\right)$ \\
\hline Language & Clinical Evaluation of Language Fundamentals $4^{\text {th }}$ ed. $\left(\mathrm{CELF}-4^{\mathrm{R}}\right)$ 14 subtests; 6 indexes \\
\hline Grammar & British Picture Vocabulary Scale (BPVS-II) \\
\hline Non-word repetition & Past Tense MorphoPhonology (PTMP), study specific measure \\
\hline Narrative & NEPSY subtest non-word repetition \\
\hline Reading & Frog-story \\
\hline Visual memory & Standardized reading test in decoding and spelling (STAS) \\
\hline Fine motor skills & Knox cubes \\
\hline
\end{tabular}

performed by asking the parents in 2000 families to complete a separate questionnaire approximately 6 months after the family received the MoBa 5-year questionnaire. The parents are asked to complete the full scale of several of the measures included in the MoBa 5-year questionnaire.

The clinical study, Language-8, utilizes MoBa data to select children/families who are asked to participate in a clinical study. The study uses 5 different criteria to select children with high risk for language impairment, (table 1). In addition, a control group is selected. Since language impairment can be part of many syndromes and general developmental delay, exclusion criteria used are based on parental reporting on any of the questionnaires about child development such as autism spectrum disorder and cerebral paresis among others. Children who at birth have major birth anomalies or syndromes affecting the brain are excluded (Based on Medical Birth Registry of Norway, MBRN) such as Down syndrome, Cleft lip and palate among others.

All families go through a phone interview after having consented to participate in the study in order to provide more detailed information about the children's language functioning. The phone interview includes items taken from the receptive subscale of the communication domain in The Vineland Adaptive Behavior Scales (VABS), a parent interview of the child's adaptive skills.

The phone interview also includes questions about early language development and delay, language impairment, spelling-, reading- and numeracy problems at the time of the phone call. They are in addition asked about presence of any disorders listed in the exclusionary criteria. All families are invited for a clinical examination unless they have reported positive on any of the exclusionary criteria defined in the study. All families who consent to participate in the clinical assessment receive a questionnaire to complete as well as a questionnaire to give to the school teacher to complete. Parents sign a written consent form that allows the researchers to ask for copies of medical records, and reports from all relevant assessments of the child.

All children seen in the Language-8 clinic go through a series of tests related to language skills as well as an IQ test and other tests relevant for language development (table 2).

In addition, both mother and child give spit samples using Orangene DNA (OG-500). Fathers and siblings who participate in $\mathrm{MoBa}$ are asked to provide saliva samples as well.

\section{RESULTS FROM PROJECTS IN SOL}

In addition to publications such as book chapters, reports and papers in a variety of Norwegian journals, eleven scientific papers have been published in international journals from the SOL platform. The results presented in the following are a summary of findings from these papers.

\section{Growth and change in language development and risk factors for language impairment}

Investigating different early predictors of language delay, Schjølberg and colleagues (2011) find that language delay (LD) at 18 months are predicted by early neurobiological factors such as male gender, birth weight, and prematurity as well as concurrent family variables such as maternal distress, low maternal education, having older siblings, or non-Norwegian language background. Overall, estimated variance in 
language outcome explained by the model was $4-7 \%$ (9). Further, Zambrana and colleagues (2012) investigated both verbal and non-verbal communication skills at 18 months and found that from 18 to 36 months of age both imitative actions, language comprehension, and language production uniquely contribute to predicting late development of language production, while pointing gestures do not (16). Further, they investigated the relationships between a number of risk factors and language comprehension, and found that at 18 and 36 months of age, first-born girls of mothers with high education have the highest level of language comprehension. They also compared language comprehension in boys and girls and found that even when boys' mothers have the highest education level, boys score below girls whose mothers have the lowest education level. Thus the conclusion from this study was that between 18 and 36 months, boys develop at a faster rate than girls, but girls still remain superior in their level of language comprehension at 36 months of age. Being firstborn or having a highly educated mother does not compensate for this lag, although both high education in mothers and being firstborn is positively related to language comprehension both in girls and boys. Zambrana and colleagues also investigated developmental trajectories of language delay from 3 to 5 years of age, and found that an integrative risk model, including poor early communicative skills, family history and male gender, predicts LD trajectories in the preschool years in quantitatively and qualitatively different ways. Persistent LD was related to poor early language comprehension and male gender. These were also risk factors for transient and late onset LD, but to a lesser degree (16).

Focusing on language in association with other neurodevelopmental outcomes, Wang and colleagues investigated developmental relations between language skills and motor skills through preschool years. Language skills was found to be associated with motor skills at both $1 \frac{1}{2}, 3$ and 5 years of age, and when controlling for the stability of development within each developmental domain motor skills at $1 \frac{1}{2}$ years of age still had a unique association to language skills at three years of age (17). From 3 to 5 years of age, controlling for the stability of each developmental domain the researchers found that language skills at three years of age uniquely predicted motor skills at five years of age, over and above what could be explained by earlier motor skills (18). Ribeiro and colleagues studied language development in children born preterm, and found that attention problems has a precursor role to language development in premature children (15).

\section{Childcare attendance and language development in preschool children}

Other researchers in the SOL study have looked at the associations between childcare and child development. Lekhal and colleagues studied children at particular risk (such as premature status, low birth weight and low Apgar score) and found that even though being in high quality day care has a positive correlation to language development, high quality day care does not buffer the relationship between biomedical birth risk and language development at 3 years of age (19). In three other studies investigating the impact on child development of attending high quality day care centers it was found that participation in center care is associated with reduced risk of language delay (20), and further that neither type of child care and age of entry (21) nor time spent in day care (22) are related to later behavior problems.

These results are also consistent with what has been presented by the SOL study in four nationally published reports. Whereas the first report gave descriptions of language development at 3 years of age (23), the following three reports describe the use of and quality in Norwegian day care centers in association to language development and other developmental areas in preschool years (24-26). The results confirmed weak associations between attendance and quality of Norwegian day care centers and language, learning and behavioral outcomes. Although this implies that for most children in Norwegian day care there are no adverse effects of attending high quality day care centers, it might be different for subgroups of children. We will therefore investigate further whether the weak associations are stronger for subgroups of vulnerable children, particularly in day care centers where quality is poor.

\section{FUTURE PERSPECTIVES}

Research on data from the school questionnaire will give us new insight into the association between school activities and language development. In particular, the questionnaire will provide information on factors in children's life at school that might influence their learning and health development as well as look at the association between language skills and learning outcomes. The questionnaire will be linked to the questionnaires completed by preschool teachers when the children were five years of age. Stability of ratings of children's development from preschool to school years will yield important insights into the transition between the preschool and school systems. In addition, teacher ratings will be compared with parent rating on the same developmental measures both at 5 and 8 years. This can shed light on contextual variations in children functions.

In collaboration with $\mathrm{KD}$, SOL will publish two popularized reports based on data from the school questionnaire, and several scientific papers based on results from analyses of these data are planned. The MoBa cohort will be followed up with a parental questionnaire when the children are 13 years of age. Predictors measured in the eight-year questionnaires, both those completed by the parent and teacher, will be investigated in relation to language and learning out- 
comes at 13 years of age. The SOL study will continue to emphasize the importance of measuring language, learning and factors encountered in the context of school in the further planning of future MoBa questionnaires.

The SOL study plans to apply to the Regional Ethical Committee for permission to link the MoBa dataset to registries containing information about childcare and school. The registry relevant for childcare is BASIL (part of KOSTRA) giving information about structural aspects of each childcare center. This is for example information about staffing, number of children, age distribution, children with special needs and available resources. The other registries relevant for school aged children is assessment tests in 1 st and 2nd grade for children living in Oslo, and additional mandatory national tests in 4th and 5th grade for all schools in Norway. This will give information about mastery of the curricule in reading, writing and numeracy.

Further, applications for grants ensuring capacity to analyze data and write scientific research papers will be emphasized in the upcoming year. The analyses of data from MoBa-questionnaires, including the CQ and SQ, will together with the biological and clinical data from Language-8, give opportunities for more precise and nuanced answers to the main research questions in SOL, namely discovering the causes and developmental trajectories leading to language impairments in children.

\section{REFERENCES}

1. Reilly S, Bavin EL, Bretherton L, Conway L, Eadie P, Cini E, et al. The Early Language in Victoria Study (ELVS): A prospective, longitudinal study of communication skills and expressive vocabulary development at 8, 12 and 24 months. Int J Speech Language Pathol 2009;11(5):344-57.

2. Tomblin JB, Records NL, Buckwalter P, Zhang X, Smith E, O'Brien M. Prevalence of specific language impairment in kindergarten children. J Speech Lang Hear Res 1997;40(6):1245-60.

3. Leonard LB. Children with specific language impairment. Cambridge, MA: MIT, 1998.

4. Catts HW, Fey ME, Tomblin JB, Zhang X. A longitudinal investigation of reading outcomes in children with language impairments. J Speech Lang Hear Res 2002;45(6):1142-57.

5. Pennington BF, Bishop DV. Relations among speech, language, and reading disorders. Annu Rev Psychol 2009;60:283-306.

6. Clegg J, Hollis C, Mawhood L, Rutter M. Developmental language disorders - a follow-up in later adult life. Cognitive, language and psychosocial outcomes. J Child Psychol Psychiatry 2005;46(2):128-49.

7. Goldston DB, Walsh A, Arnold EM, Reboussin B, Daniel SS, Erkanli A, et al. Reading Problems, Psychiatric Disorders, and Functional Impairment from Mid- to Late Adolescence. J Am Acad Child Adolesc Psychiatry 2007;46(1):25-32.

8. ...og ingen sto igjen. Tidlig innsats for livslang læring, Det kongelige kunnskapsdepartement, 2006.

9. Schjolberg S, Eadie P, Zachrisson HD, Oyen A-S, Prior M. Predicting language development at age 18 months: Data from the Norwegian Mother and Child Cohort Study. J Dev Behav Pediatr 2011;32(5):375-83.

10. Reilly S, Wake M, Bavin EL, Prior M, Williams J, Bretherton L, et al. Predicting language at 2 years of age: a prospective community study. Pediatrics 2007;120(6):e1441-e9.

11. Zubrick SR, Taylor CL, Rice ML, Slegers DW. Late language emergence at 24 months: an epidemiological study of prevalence, predictors, and covariates. J Speech Lang Hear Res 2007;50(6):1562-92.

12. Beitchman JH, Brownlie EB, Inglis A, Wild J, Mathews R, Schachter D, et al. Seven-year follow-up of speech/language-impaired and control children: speech/language stability and outcome. J Am Acad Child Adolesc Psychiatry 1994;33(9):1322-30.

13. Toppelberg CO, Shapiro T. Language disorders: a 10-year research update review. J Am Acad Child Adolesc Psychiatry 2000;39(2):143-52.

14. StatisticsNorway. Kindergarten statistics http://www.ssb.no/barnehager/: Statistics Norway; 2013 [cited 2014 September 30th].

15. Ribeiro L, Zachrisson H, Schjolberg S, Aase H, Rohrer-Baumgartner N, Magnus P. Attention problems and language development in preterm low-birth-weight children: Cross-lagged relations from 18 to 36 months. BMC Pediatr 2011;11(1):59.

16. Zambrana IM, Ystrom E, Pons F. Impact of gender, maternal education, and birth order on the development of language comprehension: A longitudinal study from 18 to 36 months of age. J Dev Behav Pediatr 2012; 33(2):146-55.

17. Wang MV, Lekhal R, Aarø LE, Schjølberg S. Co-occurring development of early childhood communication and motor skills: results from a population-based longitudinal study. Child Care Health Dev 2014;40(1):77-84.

18. Wang MV, Lekhal R, Aaro LE, Holte A, Schjolberg S. The developmental relationship between language and motor performance from 3 to 5 years of age: a prospective longitudinal population study. BMC Psychol 2014; 2(1):34. 
19. Lekhal R, von Soest T, Wang MV, Aukrust VG, Schjølberg S. Norway's high-quality center care reduces late talking in high-and low-risk groups. J Dev Behav Pediatr 2012;33(7):562-9.

20. Lekhal R, Zachrisson HD, Wang MV, Schjølberg S, von Soest T. Does universally accessible child care protect children from late talking? Results from a Norwegian population-based prospective study. Early Child Dev Care 2011;181(8):1007-19.

21. Lekhal R. Do type of childcare and age of entry predict behavior problems during early childhood? Results from a large Norwegian longitudinal study. Int J Behav Dev 2012;36(3):197-204.

22. Zachrisson HD, Dearing E, Lekhal R, Toppelberg CO. Little evidence that time in child care causes externalizing problems during early childhood in Norway. Child Dev 2013;84(4):1152-70.

23. Schjølberg S, Lekhal R, Wang MV, Zambrana IM, Mathiesen KS, Magnus P, et al. Forsinket språkutvikling En foreløpig oversikt basert på data fra Den norske mor og barn undersøkelsen. Folkehelseinstituttet, Rapport 2008:10, 2008.

24. Schjølberg S, Lekhal R, Vartun M, Helland SS, Mathiesen KS. Barnepass fram til 18 måneder. Sammenhenger mellom barnepass fram til 18 måneder og språklige ferdigheter og psykisk fungering ved 5 år. Oslo: Folkehelseinstituttet, Rapport 2011:5, 2011.

25. Lekhal R, Vartun M, Gustavson K, Helland SS, Wang MV, Schjolberg S. Den norske mor og barnundersøkelsen. Variasjon i barnehagekvalitet. Beskrivelser fra første datainnsamling fra barnehagene. Oslo: Folkehelseinstituttet, 2013.

26. Folkehelseinstituttet. Sammenhenger mellom barnehagekvalitet og barns fungering ved 5 år. Resultater fra Den norske mor og barn-undersøkelsen. Oslo: Folkehelseinstituttet, Rapport 2014:1, 2013. 